\title{
High Prevalence of Carotid Plaque Identified Using Standard Carotid Ultrasound Techniques in HIV-Positive Patients with Low to Moderate Vascular Risk
}

David Nguyen ${ }^{1}$, Vanina Stanek ${ }^{2}$, Silvia Guillemi ${ }^{1,3}$, Erin Ding ${ }^{1}$, Guillaume Colley ${ }^{1}$, Julio Montaner ${ }^{1,4}$, Viviane Lima ${ }^{1,4}$ and Gregory Bondy ${ }^{5^{*}}$

${ }^{1}$ British Columbia Centre for Excellence in HIVIAIDS, Vancouver, British Columbia, Canada

${ }^{2}$ Department of Infectious Diseases, Hospital Italiano, Buenos Aires, Argentina

${ }^{3}$ Department of Family Practice, University of British Columbia, Vancouver, British Columbia, Canada

${ }^{4}$ Division of AIDS, Department of Medicine, Faculty of Medicine, University of British Columbia, Vancouver, British Columbia, Canada

${ }^{5}$ Division of Endocrinology, Departments of Medicine and Pathology, University of British Columbia, Vancouver, British Columbia, Canada

\begin{abstract}
Background: People with HIV have an increased risk for developing atherosclerosis. The objective of our study was to measure the prevalence of carotid ultrasound abnormalities in HIV-positive patients receiving antiretroviral therapy using routine carotid ultrasound. We examined the association between abnormal carotid ultrasounds and traditional cardiovascular and HIV-related risk factors.
\end{abstract}

Methods: A cross-sectional study was carried out on male HIV-positive patients with low to moderate cardiovascular risk attending the HIV Metabolic Clinic in Vancouver, British Columbia (BC). Carotid ultrasounds were performed between January 1, 2002 and June 30, 2012, and this information was used to establish patients overall cardiovascular risk. Patient's charts were reviewed to obtain clinical data for traditional and HIV-related risk factors. Antiretroviral treatment information was obtained from the provincial Drug Treatment Program (DTP) data base. An abnormal carotid ultrasound was defined by the presence of carotid plaque(s) and was used as a surrogate marker for atherosclerotic cardiovascular disease. Powered by Editorial Manager $\circledast$ and ProduXion Manager $\circledast$ from Aries Systems Corporation

Results: A total of 175 patients receiving antiretroviral therapy since 1996 were analyzed. The prevalence of carotid ultrasound abnormality was $47 \%$. By multivariable analysis, the factors associated with carotid ultrasound abnormality included having history of high blood pressure (odds ratio $2.68,95 \%$ confidence interval $(\mathrm{Cl}): 1.17,6.13$ ) and a history of intravenous drug use (OR: $4.55,95 \% \mathrm{Cl}: 1.40,14.79)$. The odds ratios of carotid ultrasound abnormality for patients 46-55 years and $\geq 56$ years old compared to $\leq 45$ years old were 2.57 (95\% Cl: $1.08,6.14)$ and 5.16 (95\% Cl: 2.02 , 13.19) respectively. For every additional year on antiretroviral therapy, the odds ratio of abnormal carotid ultrasound increased by $1.10(95 \% \mathrm{Cl}: 1.01,1.19)$.

Conclusion: Our study suggests that HIV-positive patients assessed as having low cardiovascular risk have a high prevalence of atherosclerotic vascular disease at younger ages. Some traditional factors and longer exposure to ART were associated with carotid ultrasound abnormalities.

Keywords: HIV; Carotid ultrasound; Cardiovascular risk; Atherosclerotic cardiovascular disease; ART; HAART

\section{Introduction}

The introduction of highly active antiretroviral therapy (HAART) significantly improved the prognosis of people living with HIV [1]. As HIV-positive patients are living longer, it is becoming evident that this population has a greater prevalence of atherosclerotic cardiovascular disease than the general population [2,3]. Traditional risk factors such as hypertension, diabetes mellitus, dyslipidemia and smoking are highly prevalent among HIV-positive patients [4-6], which partly may explain the high rate of cardiovascular disease in this population. Another explanation relates to the fact that HAART may induce metabolic and anthropometric changes, which are risk factors for atherosclerotic cardiovascular disease [7,8]. HIV or HAART may accelerate atherosclerosis through unique pathways such as inflammation and endothelial dysfunction [9]. The relationship between HIV, HAART and atherosclerotic vascular disease is complex and has not been well defined.

Carotid plaque (CP) and carotid-intima-media thickness (CIMT) are validated surrogate markers of atherosclerotic cardiovascular disease that are measured by carotid ultrasound [10,11]. Previous observational studies that investigated the relationship between traditional and HIV- related risk factors and carotid surrogate markers have shown conflicting results [12]. These studies used ultrasound-imaging techniques in a research setting and computer generated estimates of CIMT. However in one study, the prevalence of carotid artery abnormalities assessed in HIV-positive patients who were not previously exposed to HAART and with no overt cardiovascular disease (CVD) was $42 \%$ [13].

The objective of our cross-sectional study was to measure the prevalence of carotid ultrasound abnormality in HIV-positive patients using conventional carotid ultrasound imaging available in a large

*Corresponding author: Gregory Bondy, Division of Endocrinology, Departments of Medicine and Pathology, University of British Columbia and Healthy Heart Program, St Paul's Hospital, 1081 Burrard St. Vancouver, British Columbia, Canada, Tel: 1-604-806-8192; E-mail: gbondy@providencehealth.bc.ca

Received June 17, 2014; Accepted June 29, 2014; Published August 12, 2014

Citation: Nguyen D, Stanek V, Guillemi S, Ding E, Colley G, et al. (2014) High Prevalence of Carotid Plaque Identified Using Standard Carotid Ultrasound Techniques in HIV-Positive Patients with Low to Moderate Vascular Risk. J AIDS Clin Res 5: 338. doi:10.4172/2155-6113.1000338

Copyright: ( 2014 Nguyen D, et al. This is an open-access article distributed unde the terms of the Creative Commons Attribution License, which permits unrestricted use, distribution, and reproduction in any medium, provided the original author and source are credited. 
tertiary teaching hospital in Vancouver, Canada. We also examined the association of carotid US abnormality with traditional and HIV-related risk factors in patients receiving HAART.

\section{Methods}

\section{Study design and population}

This cross-sectional study was carried out at the British Columbia Centre for Excellence in HIV/AIDS (BC-CfE). Clinical information was obtained from the files of patients attending the HIV Metabolic Clinic at St Paul's Hospital in Vancouver, Canada. This clinic is a medical referral center for the management of metabolic disorders in HIV-positive patients. These patients represent the HIV population in the greater Vancouver area and some areas of the province of British Columbia, Canada. As part of the standard care, patients were stratified according to cardiovascular risk during clinical evaluation. The modified Framingham Risk Score (FRS) was used to estimate the 10 -year risk of developing CVD $[14,15]$. Those who fell under lowto moderate risk, defined as a 10 -year modified FRS of $<10 \%$, or 10 to $20 \%$ respectively, were imaged with carotid ultrasounds scans to help determine cardiovascular risk assessment and to guide medical management. Participants were eligible for this study if they were 18 years or older, had a documented diagnosis of HIV and had a carotid ultrasound performed between January 1, 2002 and June 30, 2012.

\section{Data sources}

Clinical data for traditional risk factors were collected from the clinic consultation, laboratory and imaging reports. HIV-related risk factors were obtained from the HIV/AIDS Drug Treatment Program. This centralized program is managed under the $\mathrm{BC}$-CfE and coordinates the distribution of HAART in BC to all eligible residents living with HIV and free-of-charge according to specific guidelines generated by the BC-CfE's Therapeutic Guidelines Committee. These guidelines have remained consistent with those put forward by the International AIDS Society-USA since 1996 [16]. The BC-CfE maintains records of drugs dispensed and HIV serology profiles for all its patients.

Documentation of the following risk factors at the date of the carotid ultrasound were recorded: history of smoking (yes, no), intravenous drug use (yes, no, unknown), alcohol use (current, former, never), history of diabetes mellitus (yes, no), history of hypertension (yes, no), history of dyslipidemia (yes, no), history of renal insufficiency (yes, no) and age at the carotid ultrasound date (years). Anthropometric and laboratory values nearest to the date of the carotid ultrasound, within +/ 6 months were recorded. These included systolic and diastolic blood pressure $(\mathrm{mmHg})$, total cholesterol $(\mathrm{mmol} / \mathrm{L})$, highdensity lipoproteins (HDL) ( $\mathrm{mmol} / \mathrm{L})$, low-density lipoproteins (LDL) $(\mathrm{mmol} / \mathrm{L})$, triglycerides $(\mathrm{mmol} / \mathrm{L})$, apolipoprotein B (apoB) $(\mathrm{g} / \mathrm{L})$ body mass index $\left(\mathrm{kg} / \mathrm{m}^{2}\right)$, estimated glomerular filtration rate $(\mathrm{e}-\mathrm{GFR})(\mathrm{mL} /$ $\left.\mathrm{min} / 1.73 \mathrm{~m}^{2}\right)$, serum creatinine $(\mu \mathrm{mol} / \mathrm{L})$, urine albumin-creatinine ratio (ACR) (mg/mmol), C-reactive protein $(\mathrm{CRP})(\mathrm{mg} / \mathrm{L})$ and fasting blood glucose $(\mathrm{mmol} / \mathrm{L})$. Concomitant medications at the time of the carotid ultrasound were also obtained. These included lipid-lowering, anti-hypertensive and anti-diabetic medications.

The following HIV-related risk factors were recorded up to the date of the carotid ultrasound: nadir and CD4 cell count nearest to the date of the carotid ultrasound (cells $/ \mathrm{mm}^{3}$ ), peak and plasma viral load nearest to the date of the carotid ultrasound (copies/mL), previous history of AIDS at the start of antiretroviral therapy (yes, no), duration of antiretroviral therapy prior the ultrasound date (years). Other HIV-related risk factors included first antiretroviral treatment class (non-nucleoside reverse transcriptase inhibitors (NNRTI), protease inhibitors (PIs), boosted protease inhibitors (PIb), and other regimens) and baseline (i.e. prior to starting antiretroviral treatment) CD4 cell count (cells $/ \mathrm{mm}^{3}$ ) and plasma viral load (copies $/ \mathrm{mL}$ ).

\section{Carotid ultrasound}

All standard B-mode carotid ultrasounds were performed at St Paul's Hospital Radiology Department. Both carotid arteries were imaged at the level of the carotid bifurcation for carotid plaque and CIMT estimated. The carotid ultrasound report was the primary outcome variable for this study and it was recorded as either a normal or abnormal carotid ultrasound. The detection of one or more carotid plaques on ultrasound was considered abnormal, and the failure to detect carotid plaques was considered normal. Two technicians were responsible for reporting the results of the ultrasounds and the final report generated by a staff radiologist.

\section{Statistical analysis}

Categorical variables were compared using the Chi-square or the Fisher's exact test (for small counts and non-two-by-two associations), and continuous variables were compared using the Wilcoxon rank sum test. Because the extensive list of explanatory variables, we selected the significant variables associated with the carotid ultrasound result (abnormal/normal) in bivariable analyses to be potentially included as covariates in our logistic regression models. The selection of the variables for multivariable model was based on two criteria: Akaike Information Criterion (AIC) and Type III p-values [17]. These two criteria balance the model choice on finding the best explanatory model (Type III p-values - lower p-values indicate more significance) and at the same time a model with the best goodness-of-fit statistic (AIC lower values indicate better fit). At each step of this process, the AIC value and the Type III $p$-values of each variable are recorded, and the variable with the highest Type III p-value is dropped, until there are no more variables left in the model. The final model has the lowest AIC. All reported p-values are two-sided. All analyses were performed using SAS software (version 9.3).

\section{Results}

A total of 246 patients from the HIV Metabolic Clinic had a carotid ultrasound performed between January 1,2002 and June 30,2012. Of the 246 patients, 232 were males (94\%) and $14(6 \%)$ were females. Because of the low number of females, our analyses excluded these patients. To analyze the duration of protease inhibitor exposure, we focused our study on patients who had received their first antiretroviral drugs after January 1, 1996, which yielded 175 patients. Of these remaining 175 patients, 93 (53\%) had a normal carotid ultrasound (median age at ultrasound date: 47 years) and 82 (47\%) had an abnormal carotid ultrasound (median age at ultrasound date: 54 years).

As shown in the bivariable associations in Tables $1 \mathrm{a}$ and $1 \mathrm{~b}$, several traditional and HIV-related risk factors were associated with a carotid ultrasound abnormality. These included the following: age at first antiretroviral initiation; age at the time that the carotid ultrasound was performed; $<95 \%$ adherence in the first year of antiretroviral treatment; antiretroviral therapy initiation before the year 2000; history of intravenous drug use; having a protease inhibitor-based regimen and unconventional regimens as the first antiretroviral regimen; history of high blood pressure prior to the carotid ultrasound exam; being on antiretroviral treatment for a longer period of time prior to the carotid ultrasound date; and higher exposure to NNRTIs prior to the carotid ultrasound date $(\mathrm{p}<0.05)$. We categorized age at carotid ultrasound 
Page 3 of 6

\begin{tabular}{|c|c|c|c|c|c|}
\hline \multirow{2}{*}{ Characteristics } & \multicolumn{2}{|c|}{$\begin{array}{l}\text { Carotid ultrasound normal } \\
\qquad \mathrm{N}=93\end{array}$} & \multicolumn{2}{|c|}{$\begin{array}{l}\text { Carotid ultrasound abnormal } \\
\qquad \mathrm{N}=82\end{array}$} & \multirow[t]{2}{*}{ p-value } \\
\hline & $\mathbf{N}$ & (\%) & $\mathbf{N}$ & (\%) & \\
\hline \multicolumn{6}{|l|}{ Age at the carotid ultrasound date (years) } \\
\hline$\leq 45$ & 38 & (75) & 13 & (25) & $<0.001$ \\
\hline $46-55$ & 36 & (51) & 34 & (49) & \\
\hline$\geq 56$ & 19 & (35) & 35 & (65) & \\
\hline Age at the carotid ultrasound date (years) & 47 & $(42-53)$ & 54 & $(49-59)$ & $<0.001$ \\
\hline Age at antiretroviral therapy initiation date & 43 & $(36-47)$ & 47 & $(40-52)$ & 0.005 \\
\hline$\square$ & & & & & \\
\hline$<95 \%$ & 9 & (31) & 20 & (69) & 0.007 \\
\hline$\geq 95 \%$ & 81 & (59) & 57 & (41) & \\
\hline$\square$ & & & & & \\
\hline 1996-1999 & 21 & (36) & 37 & (64) & 0.005 \\
\hline $2000-2005$ & 36 & (65) & 19 & (35) & \\
\hline After 2006 & 36 & (58) & 26 & $(42)$ & \\
\hline \multicolumn{6}{|l|}{ History of injection drug use } \\
\hline No & 82 & (57) & 63 & (43) & 0.046 \\
\hline Yes & 5 & (26) & 14 & (74) & \\
\hline Unknown & 6 & (55) & 5 & (45) & \\
\hline \multicolumn{6}{|l|}{ First antiretroviral therapy regimen } \\
\hline NNRTI & 23 & (55) & 19 & (45) & 0.005 \\
\hline PI Single & 11 & (39) & 17 & (61) & \\
\hline Boosted PI & 48 & (67) & 24 & (33) & \\
\hline Other & 11 & (33) & 22 & (67) & \\
\hline \multicolumn{6}{|l|}{ Any } \\
\hline No & 69 & (53) & 60 & (47) & 0.878 \\
\hline Yes & 24 & (52) & 22 & (48) & \\
\hline Years on antiretroviral therapy before carotid ultrasound date & 5 & $(2-7)$ & 7 & $(3-12)$ & 0.008 \\
\hline Duration (years) of NNRTI exposure prior to ultrasound date & 1.30 & $(0.21-2.94)$ & 2.27 & $(1.12-5.22)$ & 0.034 \\
\hline Duration (years) of PI exposure prior to ultrasound date & 3.62 & $(1.96-5.18)$ & 4.09 & $(1.43-5.73)$ & 0.582 \\
\hline Nadir CD4 cell count (prior to ultrasound date) (cells $/ \mathrm{mm}^{3}$ ) & 140 & $(40-250)$ & 140 & $(50-190)$ & 0.795 \\
\hline CD4 value nearest to time of ultrasound (cells $\left./ \mathrm{mm}^{3}\right)$ & 500 & $(410-620)$ & 480 & $(380-600)$ & 0.268 \\
\hline Peak plasma viral load (prior to ultrasound date) (copies $/ \mathrm{mL}$ ) & 100010 & $(73900-100010)$ & 100010 & $(76378-100010)$ & 0.987 \\
\hline Plasma viral load nearest to time of ultrasound (copies $/ \mathrm{mL}$ ) & 499 & $(499-499)$ & 499 & $(499-499)$ & 0.337 \\
\hline
\end{tabular}

Note: For continuous variables, we presented the median and the $25^{\text {th }}-75^{\text {th }}$ percentiles.

Table 1a: Baseline characteristics of 175 male patients with human immunodeficiency virus who started antiretroviral therapy after 1996.

\begin{tabular}{|c|c|c|c|c|c|}
\hline \multirow[t]{2}{*}{ Characteristics } & \multicolumn{2}{|c|}{$\begin{array}{l}\text { Carotid ultrasound } \\
\text { normal } \\
\mathrm{N}=93\end{array}$} & \multicolumn{2}{|c|}{$\begin{array}{l}\text { Carotid ultrasound abnormal } \\
\qquad \mathrm{N}=82\end{array}$} & \multirow[t]{2}{*}{ p-value } \\
\hline & $\mathbf{N}$ & (\%) & $\mathbf{N}$ & $(\%)$ & \\
\hline \multicolumn{6}{|l|}{ Diabetes (at the time of ultrasound) } \\
\hline No & 87 & (55) & 70 & (45) & 0.171 \\
\hline Yes & 6 & (38) & 10 & (63) & \\
\hline \multicolumn{6}{|c|}{ History of high blood pressure (at the time of ultrasound) } \\
\hline No & 79 & (59) & 56 & (41) & 0.013 \\
\hline Yes & 14 & (36) & 25 & (64) & \\
\hline \multicolumn{6}{|c|}{ Any concurrent statin use (at the time of ultrasound) } \\
\hline No & 86 & (54) & 74 & (46) & 0.599 \\
\hline Yes & 7 & $(47)$ & 8 & (53) & \\
\hline History of smoking (at the time of ultraso & & & & & \\
\hline
\end{tabular}


Page 4 of 6

\begin{tabular}{|c|c|c|c|c|c|}
\hline No & 31 & $(63)$ & 18 & $(37)$ & 0.168 \\
\hline Yes & 46 & $(51)$ & 44 & $(49)$ & \\
\hline \multicolumn{6}{|l|}{ History of alcohol consumption (at the time of ultrasound) } \\
\hline Never & 26 & $(55)$ & 21 & $(45)$ & 0.477 \\
\hline Former & 4 & $(40)$ & 6 & $(60)$ & \\
\hline Current & 44 & $(60)$ & 29 & $(40)$ & \\
\hline \multicolumn{6}{|l|}{ History of renal failure (at the time of ultrasound) } \\
\hline No & 86 & $(54)$ & 72 & $(46)$ & 0.994 \\
\hline Yes & 6 & $(55)$ & 5 & $(45)$ & \\
\hline BMI measurement (at the time of ultrasound) $\left(\mathrm{kg} / \mathrm{m}^{2}\right)$ & 27 & $(24-29)$ & 26 & $(24-28)$ & 0.767 \\
\hline Framingham score (at time of ultrasound) & 7 & $(4-8)$ & 8 & $(5-8)$ & 0.415 \\
\hline CRP value nearest to time of ultrasound (mg/L) & 1 & $(1-3)$ & 2 & $(1-4)$ & 0.475 \\
\hline Total cholesterol value nearest to time of ultrasound ( $\mathrm{mmol} / \mathrm{L})$ & 5.44 & $(4.86-6.30)$ & 5.46 & $(4.94-6.02)$ & 0.530 \\
\hline HDL value nearest to time of ultrasound (mmol/L) & 1.09 & $(0.93-1.37)$ & 1.08 & $(0.94-1.22)$ & 0.766 \\
\hline LDL value nearest to time of ultrasound (mmol/L) & 3.22 & $(2.73-4.07)$ & 3.25 & $(2.80-3.80)$ & 0.815 \\
\hline Triglyceride value nearest to time of ultrasound ( $\mathrm{mmol} / \mathrm{L}$ ) & 2.13 & $(1.56-3.56)$ & 2.25 & $(1.41-3.18)$ & 0.625 \\
\hline apoB value nearest to time of ultrasound (g/L) & 1.11 & $(0.95-1.28)$ & 1.15 & $(0.97-1.28)$ & 0.439 \\
\hline Glucose value nearest to time of ultrasound ( $\mathrm{mmol} / \mathrm{L})$ & 5.50 & $(5.10-5.90)$ & 5.70 & $(5.30-6.00)$ & 0.055 \\
\hline
\end{tabular}

Note: * For continuous variables, we presented the median and the $25^{\text {th }}-75^{\text {th }}$ percentiles.

Table 1b: Baseline traditional cardiovascular risk factors of 175 male patients with human immunodeficiency virus.

date into three groups: $\geq 45$ years, 46 to 55 years, and $\geq 56$ years. The proportion of abnormal carotid ultrasounds was higher in patients in the older age categories as compared to patients in the younger age categories (Table 1a). There were no significant differences in laboratory results, including lipid profile, apoB, CRP, fasting blood glucose (Table $1 b$ ), and ACR, serum creatinine and e-GFR (data not-shown).

Table 2 shows the results of the univariable and multivariable logistic regression models. Of the variables associated with carotid ultrasound abnormality in Tables $1 \mathrm{a}$ and $1 \mathrm{~b}$, duration of NNRTI exposure was omitted from the models because we had data on only 77 (44\%) patients. In the multivariable model, the odds ratio of having an abnormal carotid ultrasound for patients with a history of high blood pressure was 2.68 (95\% confidence interval: $1.17,6.13)$ times higher than the odds ratio for patients without a history of high blood pressure. The odds ratio of having an abnormal carotid ultrasound for patients in the $46-55$ years and $\geq 56$ years age categories was 2.57 (95\% CI: $1.08,6.14)$ and 5.16 (95\% CI: $2.02,13.19)$ times higher than the odds ratio of patients in the $\leq 45$ years category. The odds ratio of having an abnormal carotid ultrasound for patients with a history of intravenous drug use was 4.55 (95\% CI: 1.40, 14.79) times higher than the odds ratio for patients without a history of intravenous drug use. Finally, the odds ratio of having an abnormal carotid ultrasound was 1.10 (95\% CI: $1.01,1.19)$ higher for every additional year patients were exposed to antiretroviral therapy before the carotid ultrasound date.

\section{Discussion}

We carried out a cross-sectional study on male HIV-positive patients with low to moderate cardiovascular risk. The goal was to characterize the relationship between carotid ultrasound abnormality and traditional and HIV-related risk factors in patients receiving HAART. The data for this study was obtained from January $1^{\text {st }} 2002$ to June $30^{\text {th }} 2012$. It is important to note that during this period of time there were changes to the antiretroviral therapy received by most patients which were accounted for in the analysis, but the US imaging techniques remained consistent throughout the study. Our results showed that the overall prevalence of carotid ultrasound abnormality in this study group was $47 \%$, at a median age of 54 years. These findings are higher than those found in the non-HIV infected population $(38.9 \%$ prevalence with a mean age of 55.4 years) [18]. Depairon et al. reported comparable rates in a similar cross-sectional study using carotid plaques as a surrogate marker of vascular disease in HIV and non-HIV participants [19]. Their results showed that the prevalence of carotid plaque in HIV and nonHIV controls was 55\% and 38\% respectively. Our analysis is consistent with this study, which suggests that the prevalence of atherosclerotic

\begin{tabular}{|c|c|c|}
\hline \multirow[b]{2}{*}{ Characteristic } & \multirow{2}{*}{$\begin{array}{c}\text { Bivariable } \\
\text { Odds Ratio (95\% }\end{array}$} & \multirow{2}{*}{$\begin{array}{c}\text { Multivariable } \\
\text { Odds Ratio (95\% }\end{array}$} \\
\hline & & \\
\hline \multicolumn{3}{|c|}{$\begin{array}{l}\text { First antiretroviral therapy } \\
\text { regimen }\end{array}$} \\
\hline NNRTI & $1.00(-)$ & \\
\hline PI Single & $1.55(0.69,3.46)$ & \\
\hline Boosted PI & $2.85(1.13,7.22)$ & \\
\hline Other & $4.60(1.86,11.35)$ & \\
\hline \multicolumn{3}{|c|}{ History of high blood pressure (at the time of ultrasound) } \\
\hline No & $1.00(-)$ & $1.00(-)$ \\
\hline Yes & $2.51(1.19,5.29)$ & $2.68(1.17,6.13)$ \\
\hline \multicolumn{3}{|c|}{ Age at carotid ultrasound date } \\
\hline$\leq 45$ & $1.00(-)$ & $1.00(-)$ \\
\hline $46-55$ & $2.60(1.18,5.75)$ & $2.57(1.08,6.14)$ \\
\hline$\geq 56$ & $4.90(2.08,11.56)$ & $5.16(2.02,13.19)$ \\
\hline \multicolumn{3}{|c|}{$\square$} \\
\hline$<95 \%$ & $1.00(-)$ & $1.00(-)$ \\
\hline$\geq 95 \%$ & $0.31(0.13,0.73)$ & $0.45(0.17,1.20)$ \\
\hline \multicolumn{3}{|c|}{ History of injection drug use } \\
\hline No & $1.00(-)$ & $1.00(-)$ \\
\hline Yes & $3.81(1.3,11.18)$ & $4.55(1.40,14.79)$ \\
\hline Unknown & $0.91(0.25,3.36)$ & $1.43(0.35,5.79)$ \\
\hline $\begin{array}{l}\text { Years on antiretroviral } \\
\text { therapy before carotid } \\
\text { ultrasound date }\end{array}$ & $1.12(1.04,1.20)$ & $1.10(1.01,1.19)$ \\
\hline
\end{tabular}

Table 2: Results of the logistic regression models modeling the probability of carotid ultrasound abnormality. 
disease in the HIV population is higher than the general population.

In this study, we demonstrated that carotid ultrasound abnormality was associated with age at carotid ultrasound date, history of high blood pressure, history of injection drug use and years on antiretroviral therapy before carotid ultrasound date. Age and hypertension are traditional risk factors that are well established in predicting cardiovascular morbidity and mortality in HIV-infected and uninfected individuals [20,21]. In an Italian study up to $30 \%$ of HIV-positive patients had a diagnosis of hypertension, and over one third of the cohort were not aware of their condition [22]. Our results are consistent with the literature and they support the notion that certain traditional risk factors for HIV disease progression are important contributors to atherosclerotic disease in the HIV population. Previous observational studies that investigated the relationship between traditional risk factors and carotid ultrasound surrogate markers in HIV patients have found similar results [23-26]. However, our analysis failed to demonstrate a significant association between carotid ultrasound abnormality and other traditional risk factors such as dyslipidemia, diabetes mellitus, hypertension and smoking. This can be explained by our relatively young population, the fact that we included patients with low to moderate cardiovascular risk, and the small sample size in this study. There may also be additional factors unrelated to the traditional risk factors, which may explain these findings, including inflammation related to HIV infection and use of certain antiretrovirals.

It is hypothesized that certain protease inhibitors induce unfavorable lipid profiles that contribute to atherosclerotic disease [27]. In the Data Collection on Adverse Events of Anti-HIV Drugs (DAD) study, the rate of myocardial infarctions for HIV patients who were exposed to protease inhibitors for one year was 1.16 times the rate of HIV patients who were not exposed to protease inhibitors [28]. After adjusting for serum lipid levels, the relative risk remained significant at 1.10 , suggesting that protease inhibitors contribute to cardiovascular disease through different mechanisms. Previous observational studies that investigated the relationship between protease inhibitor and carotid plaques produced conflicting results [19,23,29-31]. Maggi demonstrated that protease inhibitor exposure was associated with carotid plaques $[29,30]$ while other observational studies failed to show this association $[19,23,31]$. Although protease inhibitor exposure was not significantly associated with abnormal carotid ultrasound in our analysis, we found that longer duration of antiretroviral therapy was associated with an abnormal result. This finding was also found in an observational study by Jericho [25]. One possible explanation for why we were unable to detect a significant association with protease inhibitors exposure could be related to the short follow-up time in our study. The median years of protease inhibitor exposure prior to the ultrasound date for patients with normal and abnormal carotid ultrasound was $3.62(1.96,5.18)$ and $4.09(1.43,5.73)$ years respectively.

Inflammation plays a major role in the pathogenesis of atherosclerotic cardiovascular disease [32]. CRP is an inflammatory marker that is associated with cardiovascular events in the general population [33]. The Jupiter trial selected individuals with a CRP $>2.0$ $\mathrm{mg} / \mathrm{L}$ and an $\mathrm{LDL}<3.5 \mathrm{mmol} / \mathrm{L}$ in the absence of vascular disease. This trial showed that rosuvastatin was effective in reducing cardiovascular events in this group of patients. The reduction in cardiovascular events may be related to a decrease in CRP [34]. Due to their state of chronic inflammation, CRP was elevated in the HIV-positive population and it was an independent risk factor for acute myocardial infarctions [35,36]. Elevated CRP in the HIV-positive population was found to be associated with abnormal carotid surrogate markers in several observational studies [37,38]. Our analysis failed to detect a significant association between CRP and carotid ultrasound abnormality. As previously stated, the HIV Metabolic Clinic is an outpatient medical service that actively treats metabolic disorders in healthy and virallysuppressed HIV-positive patients. The effect of antiretroviral therapy on viral suppression may have decreased serum CRP and obscured our ability to detect an association of CRP and an abnormal carotid ultrasound $[34,39,40]$.

The strength of our study was to confirm the high prevalence of carotid US abnormalities in a group representative of HIV-positive patients in British Columbia, Canada, with low to moderate risk for CVD receiving HAART. Our findings highlight the importance of early intervention and risk factor modifications in this population. Second, this study was based on patients with free access to medical care, antiretroviral therapy, and laboratory monitoring. Some limitations were identified in this investigation. First, the cross-sectional nature of this study made it difficult to establish the temporal relationship between the exposure of risk factors and the development of carotid plaque. However, the presence of a dose-response relationship between duration of antiretroviral therapy exposure and prevalence of carotid plaques increased our confidence in a temporal relationship. Second, his study used a surrogate marker instead of a defined end point such as the incidence of myocardial infarction. Carotid plaque and CIMT are validated surrogate markers of cardiovascular disease [10,11]; they are frequently used as clinical endpoints in research and used for risk stratification in patient care [41,42]. Third, it is important to mention that carotid ultrasounds were more frequently performed in recent years due to changes in the standard of care in our clinic. Finally, although we adjusted our analyses for several demographical and clinical characteristics, as in all observational studies unmeasured differences may exist among study populations, and for this reason, our findings should be interpreted with caution.

In conclusion, this study suggests that in this group of HIV-positive patients there is a high prevalence of atherosclerotic disease. Unlike previous studies, carotid plaque was identified using conventional carotid ultrasound techniques available at our center. This suggests that conventional carotid ultrasound imaging is a useful technique to screen HIV patients for plaque and this information can be used to determine their overall vascular risk. This is consistent with vascular risk assessment guidelines that suggest that HIV is an inflammatory condition that increases vascular risk [14]. Our study showed that duration of antiretroviral therapy, age, hypertension and history of intravenous drug use were associated with the risk of having an abnormal carotid ultrasound result. Consequently a strong emphasis should be placed on modifying traditional risk factors when optimizing cardiovascular care for HIV-positive patients. Further research is required to validate our findings in a more representative study population of HIV-positive patients on antiretroviral treatment.

\section{Acknowledgements}

We would like to acknowledge the work of Julia Dahlby in helping the authors prepare this manuscript for submission.

\section{References}

1. Moore RD, Chaisson RE (1999) Natural history of HIV infection in the era of combination antiretroviral therapy. AIDS 13: 1933-1942.

2. Antiretroviral Therapy Cohort Collaboration (2010) Causes of death in HIV-1infected patients treated with antiretroviral therapy, 1996-2006: collaborative analysis of 13 HIV cohort studies. Clin Infect Dis 50: 1387-1396.

3. Klein D, Hurley LB, Quesenberry CP Jr, Sidney S (2002) Do protease inhibitors increase the risk for coronary heart disease in patients with HIV-1 infection? J 
Acquir Immune Defic Syndr 30: 471-477.

4. Khot UN, Khot MB, Bajzer CT, Sapp SK, Ohman EM, et al. (2003) Prevalence of conventional risk factors in patients with coronary heart disease. JAMA 290: 898-904.

5. Saves M, Chene G, Ducimetiere P, Leport C, Le Moal G, et al. (2003) Risk factors for coronary heart disease in patients treated for human immunodeficiency virus infection compared with the general population. Clin Infect Dis 37: 292-298.

6. Triant VA, Lee H, Hadigan C, Grinspoon SK (2007) Increased acute myocardial infarction rates and cardiovascular risk factors among patients with human immunodeficiency virus disease. J Clin Endocrinol Metab 92: 2506-2512.

7. Carr A, Samaras K, Thorisdottir A, Kaufmann GR, Chisholm DJ, et al. (1999) Diagnosis, prediction, and natural course of HIV-1 protease-inhibitor-associated lipodystrophy, hyperlipidaemia, and diabetes mellitus: a cohort study. Lancet 353:2093-2099.

8. Grunfeld C, Pang M, Doerrler W, Shigenaga JK, Jensen P, et al. (1992) Lipids, lipoproteins, triglyceride clearance, and cytokines in human immunodeficiency virus infection and the acquired immunodeficiency syndrome. J Clin Endocrinol Metab 74: 1045-1052.

9. Currier JS, Lundgren JD, Carr A, Klein D, Sabin CA et al. (2008) Epidemiological evidence for cardiovascular disease in HIV-infected patients and relationship to highly active antiretroviral therapy. Circulation 118: 29-35.

10. Chambless LE, Heiss G, Folsom AR, Rosamond W, Szklo M, et al. (1997) Association of coronary heart disease incidence with carotid arterial wall thickness and major risk factors: the Atherosclerosis Risk in Communities (ARIC) Study, 1987-1993. Am J Epidemiol 146: 483-494.

11. Longenecker CT, Hoit BD (2012) Imaging atherosclerosis in HIV: carotid intimamedia thickness and beyond. Transl Res 159: 127-139.

12. Hulten E, Mitchell J, Scally J, Gibbs B, Villines TC (2009) HIV positivity, protease inhibitor exposure and subclinical atherosclerosis: a systematic review and meta-analysis of observational studies. Heart 95: 1826-1835.

13. De Socio GV, Martinelli C, Ricci E, Orofino G, Valsecchi L, et al. (2010) Relations between cardiovascular risk estimates and subclinical atherosclerosis in naive HIV patients: results from the HERMES study. Int J STD AIDS 21: 267-272.

14. Anderson TJ, Grégoire J, Hegele RA, Couture P, Mancini GB, et al. (2013) 2012 update of the Canadian Cardiovascular Society guidelines for the diagnosis and treatment of dyslipidemia for the prevention of cardiovascular disease in the adult. Can J Cardiol 29: 151-167.

15. D'Agostino RB Sr, Vasan RS, Pencina MJ, Wolf PA, Cobain M, et al. (2008) General cardiovascular risk profile for use in primary care: the Framingham Heart Study. Circulation 117: 743-753.

16. Thompson MA, Aberg JA, Hoy JF, Telenti A, Benson C, et al. (2012) Antiretrovira treatment of adult HIV infection: 2012 recommendations of the International Antiviral Society-USA panel. JAMA 308: 387-402.

17. Lima VD, Nosyk B, Wood E, Kozai T, Zhang W, et al. (2012) Assessing the effectiveness of antiretroviral regimens in cohort studies involving HIV-positive injection drug users. AIDS 26: 1491-1500.

18. Fabris F, Zanocchi M, Bo M, Fonte G, Poli L, et al. (1994) Carotid plaque, aging, and risk factors. A study of 457 subjects. Stroke 25: 1133-1140.

19. Depairon M, Chessex S, Sudre P, Rodondi N, Doser N, et al. (2001) Premature atherosclerosis in HIV-infected individuals--focus on protease inhibitor therapy. AIDS 15: 329-334.

20. Kannel WB (1996) Blood pressure as a cardiovascular risk factor: prevention and treatment. JAMA 275: 1571-1576.

21. Cooney MT, Vartiainen E, Laatikainen T, De Bacquer D, McGorrian C, et al. (2012) Cardiovascular risk age: concepts and practicalities. Heart 98: 941-946.

22. De Socio GV, Ricci E, Maggi P, Parruti G, Pucci G, et al. (2014) Prevalence, awareness, treatment, and control rate of hypertension in HIV-infected patients: the HIV-HY study. Am J Hypertens 27: 222-228.

23. Alonso-Villaverde C, Coll B, Parra S, Montero M, Calvo N, et al. (2004) Atherosclerosis in patients infected with HIV is influenced by a mutant monocyte chemoattractant protein-1 allele. Circulation 110: 2204-2209.

24. Hsue PY, Lo JC, Franklin A, Bolger AF, Martin JN, et al. (2004) Progression of atherosclerosis as assessed by carotid intima-media thickness in patients with HIV infection. Circulation 109: 1603-1608.

25. Jericó C, Knobel H, Calvo N, Sorli ML, Guelar A, et al. (2006) Subclinical carotid atherosclerosis in HIV-infected patients: role of combination antiretroviral therapy. Stroke 37: 812-817.

26. Mangili A, Gerrior J, Tang AM, O'Leary DH, Polak JK, et al. (2006) Risk of cardiovascular disease in a cohort of HIV-infected adults: a study using carotid intima-media thickness and coronary artery calcium score. Clin Infect Dis 43 : 1482-1489.

27. Stein JH, Klein MA, Bellehumeur JL, McBride PE, Wiebe DA, et al. (2001) Use of human immunodeficiency virus-1 protease inhibitors is associated with atherogenic lipoprotein changes and endothelial dysfunction. Circulation 104 257-262.

28. DAD Study Group, Friis-Møller N, Reiss P, Sabin CA, Weber R, et al. (2007) Class of antiretroviral drugs and the risk of myocardial infarction. N Engl J Med 356: $1723-1735$.

29. Maggi P, Serio G, Epifani G, Fiorentino G, Saracino A, et al. (2000) Premature lesions of the carotid vessels in HIV-1-infected patients treated with protease inhibitors. AIDS 14: F123-128.

30. Maggi P, Lillo A, Perilli F, Maserati R, Chirianni A; PREVALEAT Group (2004) Colour-Doppler ultrasonography of carotid vessels in patients treated with antiretroviral therapy: a comparative study. AIDS 18: 1023-1028.

31. Seminari E, Pan A, Voltini G, Carnevale G, Maserati R, et al. (2002) Assessment of atherosclerosis using carotid ultrasonography in a cohort of HIV-positive patients treated with protease inhibitors. Atherosclerosis 162: 433-438.

32. Ross R (1999) Atherosclerosis--an inflammatory disease. N Engl J Med 340: 115-126.

33. Buckley DI, Fu R, Freeman M, Rogers K, Helfand M (2009) C-reactive protein as a risk factor for coronary heart disease: a systematic review and metaanalyses for the U.S. Preventive Services Task Force. Ann Intern Med 151: 483-495.

34. Ridker PM, Danielson E, Fonseca FA, Genest J, Gotto AM Jr, et al. (2008) Rosuvastatin to prevent vascular events in men and women with elevated C-reactive protein. N Engl J Med 359: 2195-2207.

35. Noursadeghi M, Miller RF (2005) Clinical value of C-reactive protein measurements in HIV-positive patients. Int J STD AIDS 16: 438-441.

36. Triant VA, Meigs JB, Grinspoon SK (2009) Association of C-reactive protein and HIV infection with acute myocardial infarction. J Acquir Immune Defic Syndr 51: 268-273.

37. Ross AC, Rizk N, O'Riordan MA, Dogra V, El-Bejjani D, et al. (2009) Relationship between inflammatory markers, endothelial activation markers, and carotid intima-media thickness in HIV-infected patients receiving antiretroviral therapy. Clin Infect Dis 49: 1119-1127.

38. Hsue PY, Hunt PW, Schnell A, Kalapus SC, Hoh R, et al. (2009) Role of vira replication, antiretroviral therapy, and immunodeficiency in HIV-associated atherosclerosis. AIDS 23: 1059-1067.

39. Lau B, Sharrett AR, Kingsley LA, Post W, Palella FJ, et al. (2006) C-reactive protein is a marker for human immunodeficiency virus disease progression. Arch Intern Med 166: 64-70.

40. Aslangul E, Fellahi S, Assoumou LK, Bastard JP, Capeau J, et al. (2011) Highsensitivity C-reactive protein levels fall during statin therapy in HIV-infected patients receiving ritonavir-boosted protease inhibitors. AIDS 25: 1128-1131.

41. Inaba Y, Chen JA, Bergmann SR (2012) Carotid plaque, compared with carotid intima-media thickness, more accurately predicts coronary artery disease events: a meta-analysis. Atherosclerosis 220: 128-133.

42. Stein JH, Korcarz CE, Hurst RT, Lonn E, Kendall CB, et al. (2008) Use of carotid ultrasound to identify subclinical vascular disease and evaluate cardiovascular disease risk: a consensus statement from the American Society of Echocardiography Carotid Intima-Media Thickness Task Force. Endorsed by the Society for Vascular Medicine. J Am Soc Echocardiogr 21: 93-111. 